\title{
Breast Adenomyoepithelial Adenosis
}

National Cancer Institute

\section{Source}

National Cancer Institute. Breast Adenomyoepithelial Adenosis. NCI Thesaurus. Code C40391.

An uncommon variant of breast adenosis characterized by the presence of irregularly shaped glands, epithelial cells with eosinophilic cytoplasm, and prominent myopepithelial cells. Mild atypia may be present. 